\title{
Bridgman growth of bismuth tellurite crystals
}

\author{
ANHUA WU, JIAYUE XU*, GUOXING QIAN, BAOLIANG LU, ZENGWEI GE, \\ LINYAO TANG and XIANJUN WU \\ Shanghai Institute of Ceramics, Chinese Academy of Sciences, 1295 Dingxi Road, Shanghai 200050, People's Republic \\ of China
}

MS received 23 February 2005

\begin{abstract}
The photorefractive crystal, $\mathrm{Bi}_{2} \mathrm{TeO}_{5}$, was grown by the modified Bridgman method for the first time. High purity $\mathrm{Bi}_{2} \mathrm{O}_{3}$ and $\mathrm{TeO}_{2}$ were used as starting materials and were mixed thoroughly with molar ratio of $\mathrm{Bi}_{2} \mathrm{O}_{3} / \mathrm{TeO}_{2}=1: 1$. Platinum crucible was fabricated with a seed well of $10 \mathrm{~mm}$ in diameter and several folds were pressed so that the spontaneous nuclei could be eliminated through competition. The crucible was sealed during the growth so that the evaporation of $\mathrm{TeO}_{2}$ was controlled effectively. By optimizing growth parameters, transparent and crack-free $\mathrm{Bi}_{2} \mathrm{TeO}_{5}$ crystal up to $25 \mathrm{~mm}$ in diameter and $40 \mathrm{~mm}$ in length was grown successfully.
\end{abstract}

Keywords. $\mathrm{Bi}_{2} \mathrm{TeO}_{5}$ crystal; Bridgman; photorefractive materials.

\section{Introduction}

Volume holographic memories have been widely investigated during the last decade and have demonstrated their advantages in terms of storage capacity and fast read-out speed (Berger et al 2003). However, volume holographic storage system still suffers from the lack of an appropriate memory material. Such a material has to fulfill a series of properties, for example, high sensitivity, good optical quality, non-volatile, etc. These storage materials can be photorefractive inorganic crystals, polymers or doped glasses. So far, photorefractive $\mathrm{LiNbO}_{3}$ crystal is still the most important crystal material for the volume holographic storage application. However, the vulnerability of the holograms is the major shortcoming of $\mathrm{LiNbO}_{3}$ crystal. The more practical fixing approach was realized by using doubly, Fe and $\mathrm{Mn}$ doped photochromic $\mathrm{LiNbO}_{3}$, which caused many difficulties in crystal growth. Recently, bismuth tellurite $\left(\mathrm{Bi}_{2} \mathrm{TeO}_{5}\right)$ has attracted much attention as a new photorefractive material (Foldvari et al 1990; Berger et al 2003). $\mathrm{Bi}_{2} \mathrm{TeO}_{5}$ crystals demonstrate a long living (more than 6 years) photorefractive signal component that developed in the four-wave-mixing (FWM) write process without any specific fixing. In addition, its photorefractive sensitivity is about hundred times more than that of $\mathrm{LiNbO}_{3}$ crystals (Foldvari et al 1992; Peter et al 1996). This suggests that $\mathrm{Bi}_{2} \mathrm{TeO}_{5}$ crystal might be an ideal material for holographic memory application.

So far, all of $\mathrm{Bi}_{2} \mathrm{TeO}_{5}$ crystals have been grown by Czochralski method (Foldvari et al 1999; Kumaragurubaran et al 2000). It is difficult to grow large size and high quality $\mathrm{Bi}_{2} \mathrm{TeO}_{5}$ crystals due to the cracking and

*Author for correspondence (crystalxu@ mail.sic.ac.cn) evaporation of $\mathrm{TeO}_{2}$ during the crystal growth process. Thus, $\mathrm{Bi}_{2} \mathrm{TeO}_{5}$ crystals had been grown by Czochralski methods through adjusting the $\mathrm{Bi}_{2} \mathrm{O}_{3} / \mathrm{TeO}_{2}$ ratio in the starting composition. However, the chemical inhomogeneity of the crystal hindered its application (Foldvari et al 1999). To our knowledge, the vertical Bridgman method has obvious advantages such as (a) controlling crystal cracking due to its lower temperature gradient in solidliquid interface and (b) suppressing component evaporation because the melt could be sealed in the small space of the crucible. In the present work, the vertical Bridgman method was employed to grow $\mathrm{Bi}_{2} \mathrm{TeO}_{5}$ crystals for the first time and the preliminary results are reported here.

\section{Experimental}

Chemical reagents, $\mathrm{TeO}_{2}(4 \mathrm{~N})$ and $\mathrm{Bi}_{2} \mathrm{O}_{3}(4 \mathrm{~N})$, were used as starting materials and were weighed with the molar ratio of $\mathrm{Bi}_{2} \mathrm{O}_{3}: \mathrm{TeO}_{2}=1: 1$. They were mixed thoroughly with an agate mortar and pestle, and then were loaded into a platinum crucible with a dimension of $25 \mathrm{~mm}$ in diameter and $250 \mathrm{~mm}$ in length. A seed well of $\Phi 10 \times$ $60 \mathrm{~mm}$ was designed in the bottom of the crucible. After charging, the crucible was sealed to prevent component deviation from stoichiometric composition due to the evaporation of $\mathrm{TeO}_{2}$ and sintered in a muffle furnace. Polycrystalline $\mathrm{Bi}_{2} \mathrm{TeO}_{5}$ raw materials were synthesized by a two-step solid-phase reaction. The first step was conducted at $650^{\circ} \mathrm{C}$ in a Pt crucible for $24 \mathrm{~h}$. The melting temperature of $\mathrm{TeO}_{2}$ being $733^{\circ} \mathrm{C}$, higher reaction temperature may result in the evaporation of $\mathrm{TeO}_{2}$ component and the formation of other phases (Szaller et al 1996). Then the reaction was completed by a subsequent heating treatment at $750^{\circ} \mathrm{C}$ for $24 \mathrm{~h}$. 
The crucible was put into the refractory tube, which was filled with $\mathrm{Al}_{2} \mathrm{O}_{3}$ powder to support the crucible as well as to isolate it from external temperature fluctuations. Two pairs of $\mathrm{Pt}-\mathrm{Pt} / \mathrm{Rh}$ thermocouples were installed in the tube to measure the temperature of the melt and the bottom of the seed well. Crystal growth was carried out in a home-made vertical Bridgman furnace. Powder $\mathrm{X}$-ray diffraction $(\mathrm{XRD}, \mathrm{D} / \max 2250 \mathrm{~V}$ ) was performed to examine the phase structure of as-grown crystals.

\section{Results and discussion}

\subsection{Control of Bi/Te ratio}

$\mathrm{Bi}_{2} \mathrm{TeO}_{5}$ single crystal was previously grown by the Czochralski method, and there was no report about other growth techniques so far. Due to the cracking and the high evaporation of $\mathrm{TeO}_{2}$ component, it is difficult to obtain large size and high quality $\mathrm{Bi}_{2} \mathrm{TeO}_{5}$ crystals. In order to compensate the loss of $\mathrm{TeO}_{2}$ component during the sintering and growth process, both Foldvari et al (1999) and Kumaragurubaran et al (2000) used the starting materials with the molar ratio of $\mathrm{Bi}_{2} \mathrm{O}_{3}: \mathrm{TeO}_{2}=0.925$ : 1.05 to grow $\mathrm{Bi}_{2} \mathrm{TeO}_{5}$ single crystal. Furthermore, an excess of $\mathrm{TeO}_{2}$ may minimize the risk of the harmful reaction of $\mathrm{Bi}_{2} \mathrm{O}_{3}$ with platinum crucible. However, the compositions of as-grown $\mathrm{Bi}_{2} \mathrm{TeO}_{5}$ crystal varied from $50.5 \mathrm{~mol} \% \mathrm{TeO}_{2}$ at the top to $52.9 \mathrm{~mol}^{2} \mathrm{TeO}_{2}$ at the bottom, and only $70 \%$ of the melt was crystallized (Foldvari et al 1999; Kumaragurubaran et al 2000).

According to our previous work on the crystal growth of $\mathrm{Pb}_{5} \mathrm{Ge}_{3} \mathrm{O}_{11}$ and $\mathrm{Sr}_{3} \mathrm{Ga}_{2} \mathrm{Ge}_{4} \mathrm{O}_{14}$, the evaporation of the compositions can be controlled effectively by sealing the melt in small space of the crucible during the crystal growth (Ding et al 2004; Wu et al 2004). Therefore, the sealed crucible was employed to synthesize polycrystalline $\mathrm{Bi}_{2} \mathrm{TeO}_{5}$ and grow the crystal. The starting materials with the molar ratio of $\mathrm{Bi}_{2} \mathrm{O}_{3}: \mathrm{TeO}_{2}=1: 1$ was used and nearly all of the melt transformed into $\mathrm{Bi}_{2} \mathrm{TeO}_{5}$ crystals.

\subsection{Optimum of growth parameters}

The furnace temperature was set to about $80^{\circ} \mathrm{C}$ higher than that of its melting point $\left(900 \pm 5^{\circ} \mathrm{C}\right)$, so that the polycrystalline $\mathrm{Bi}_{2} \mathrm{TeO}_{5}$ melted thoroughly. Two pairs of $\mathrm{Pt}-\mathrm{Pt} / \mathrm{Rh}$ thermocouples were installed in the refractory tube. The upper one showed the temperature of $\mathrm{Bi}_{2} \mathrm{TeO}_{5}$ melt near the middle of the crucible and the lower one showed the temperature near the bottom of the seed well. The position of the crucible in the furnace was adjusted by a mechanism. When the lower thermocouple showed a temperature $15^{\circ} \mathrm{C}$ higher than the melting point of $\mathrm{Bi}_{2} \mathrm{TeO}_{5}$, the crucible began to descend at the rate of $0 \cdot 2-$ $0.6 \mathrm{~mm} / \mathrm{h}$. The growth cycle was calculated based on the growth rate and size of the crucible in advance. After all the melt solidified, the crucible lowering was stopped and the furnace was cooled down to room temperature at a rate of about $50^{\circ} \mathrm{C} / \mathrm{h}$.

In order to eliminate the spontaneous nuclei through competition, the seed well of the crucible was pressed with several folds, as schematically shown in figure 1. When the temperature value of the bottom thermocouples reached $915^{\circ} \mathrm{C}$, the crucible was held for $5 \mathrm{~h}$ so that a homogeneous melt was accomplished. Then the crucible was pulled down $5 \sim 10 \mathrm{~mm}$ suddenly to form fast cooling nuclei. Single crystal seed was obtained through competition of these nuclei in the folded seed well. Figure 2 shows a typical as-grown $\mathrm{Bi}_{2} \mathrm{TeO}_{5}$ crystal. The crystal was slightly yellow and transparent, and the length of the cylindrical part was about $70 \mathrm{~mm}$ with a diameter of $25 \mathrm{~mm}$. The top part of as-grown crystal was dark yellow and only small amount of residual melt was found. This demonstrated that nearly all of the melt crystallized during the Bridgman growth. However, some cracks were observed in the end of the crystal. These cracks always had an inclination angle of about $20^{\circ}$ with the growth direction. They were mainly induced by the residual having different thermal properties in comparison with the crystal. The inclination of the crack may be attributed to the existence of cleavage plane, which will be discussed in the next section. Table 1 shows the optimal growth parameters for the Bridgman growth of 1-inch $\mathrm{Bi}_{2} \mathrm{TeO}_{5}$ crystals. The growth of 2 -inch $\mathrm{Bi}_{2} \mathrm{TeO}_{5}$ crystals had been tried several times but some problems were often encountered. One of the problems was the leakage of the melt from the shouldering part of the crucible, as shown in figure 3 . The platinum crucible might be etched by $\mathrm{Bi}_{2} \mathrm{O}_{3}$ component during crystal growth. It is better

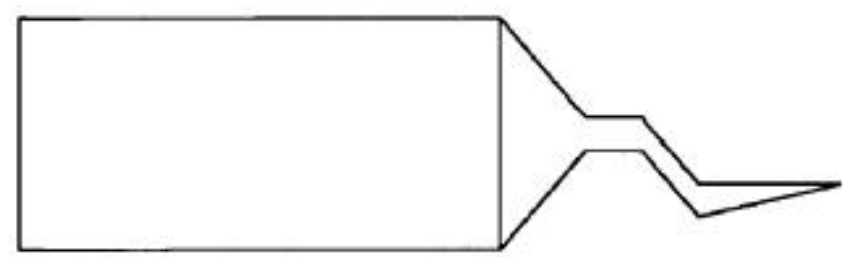

Figure 1. Schematic of the platinum crucible for the nuclei competition.

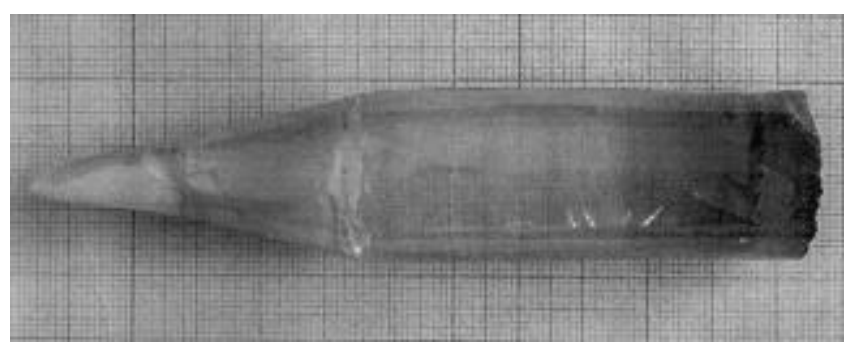

Figure 2. As-grown $\mathrm{Bi}_{2} \mathrm{TeO}_{5}$ crystal by the modified Bridgman method. 
to grow $\mathrm{Bi}_{2} \mathrm{TeO}_{5}$ crystal using polycrystalline $\mathrm{Bi}_{2} \mathrm{TeO}_{5}$ powder.

\subsection{Crystal characterization}

Powder X-ray diffraction (XRD) data of $\mathrm{Bi}_{2} \mathrm{TeO}_{5}$ crystal sample were collected on a Rigaku D/Max-2250 V diffractometer with $\mathrm{CuK} \alpha$ radiation of wavelength $\lambda=$ $1.5418 \AA$ at room temperature $(28 \mathrm{kV}, 20 \mathrm{~mA}$, fixed scattering and divergence slits of $1^{\circ}$ and a receiving slit of $0.15 \mathrm{~mm}$ ). Intensities for the diffraction peaks were recorded in the $10-70^{\circ}(2 \theta)$ range with a step size of $0.02^{\circ}$ and a scan speed of $10 \% \mathrm{~min}$ as shown in figure 4 . The XRD experiments agreed well with JCPDS card No. 761971. $\mathrm{Bi}_{2} \mathrm{TeO}_{5}$ crystal belongs to orthorhombic symmetry of space group $C_{2 v}^{15}$ and the lattice constants were calculated as $a=1.155 \mathrm{~nm}, b=1.640 \mathrm{~nm}$ and $c=0.550 \mathrm{~nm}$.

The as-grown crystals were cut by a diamond saw and polished mechanically with $0 \cdot 1 \mu \mathrm{m}$ diamond paste. X-ray orientation showed that crystallographic direction <213> was the preferable growth direction of $\mathrm{Bi}_{2} \mathrm{TeO}_{5}$ crystal. In order to check single crystallinity of as-grown crystal, the cross-section was polished and immersed in hydro-

Table 1. The technical parameters for Bridgman growth of $\mathrm{Bi}_{2} \mathrm{TeO}_{5}$ crystals.

\begin{tabular}{ll}
\hline Crucible material & Platinum \\
Crucible size $(\mathrm{mm})$ & $\Phi 10 \times 60+\Phi 25 \times 250$ \\
Furnace temperature $\left({ }^{\circ} \mathrm{C}\right)$ & $950-1000$ \\
Precision of temperature controlling $\left({ }^{\circ} \mathrm{C}\right)$ & $0 \cdot 5$ \\
Growth rate $(\mathrm{mm} / \mathrm{h})$ & $0 \cdot 2-0 \cdot 6$ \\
Temperature gradient $\left({ }^{\circ} \mathrm{C} / \mathrm{cm}\right)$ & $15 \sim 30$ \\
Period of growth $($ day $)$ & 15 \\
\hline
\end{tabular}

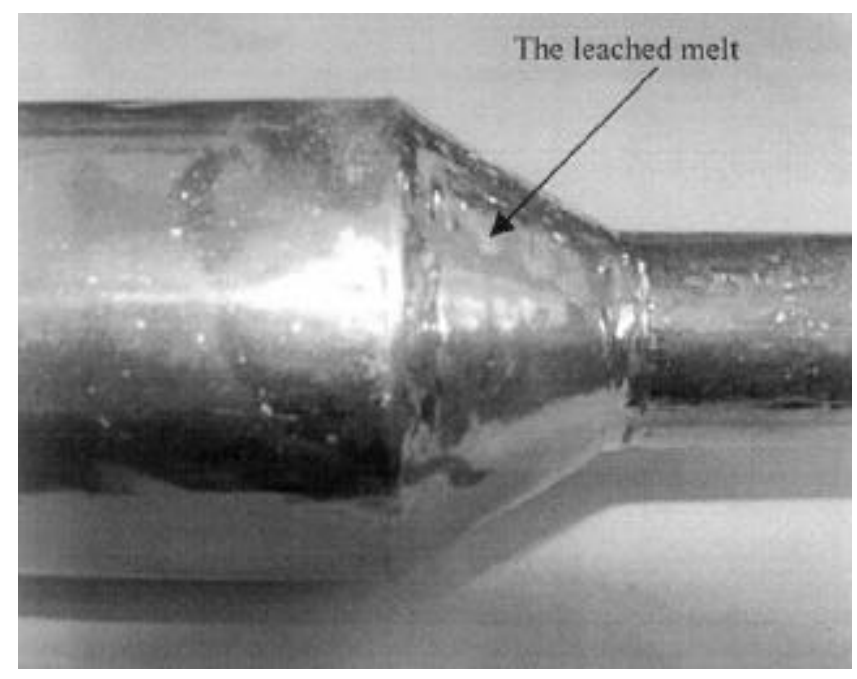

Figure 3. The platinum crucible etched by the melt. chloric acid solution (volume ratio of $\mathrm{HCl}$ : water $=1: 3$ ) for $5 \mathrm{~min}$. No crystal boundary or twin was observed in the section.

As described in the above section, cracking always occurred in the top part with an inclination angle of about $20^{\circ}$ to the growth direction, which is shown as figure 5 . All of the cracking planes looked smooth and were determined as (100) face by X-ray orientation. So the cracking plane was suggested to be a cleavage plane of $\mathrm{Bi}_{2} \mathrm{TeO}_{5}$ crystal. The same problem was also met in Czochralski growth of $\mathrm{Bi}_{2} \mathrm{TeO}_{5}$ crystal (Foldvari et al 1990). In fact, $\mathrm{Bi}_{2} \mathrm{TeO}_{5}$ crystal is easy to crack during cutting and polishing process as well as crystal growth. A small temperature gradient was employed in the growth and an in situ annealing system was assembled in the lower temperature zone of the furnace. As-grown crystal was moved to this zone and annealed for several hours when the crystal growth finished. By this way, the occurrence of cracking was reduced considerably.

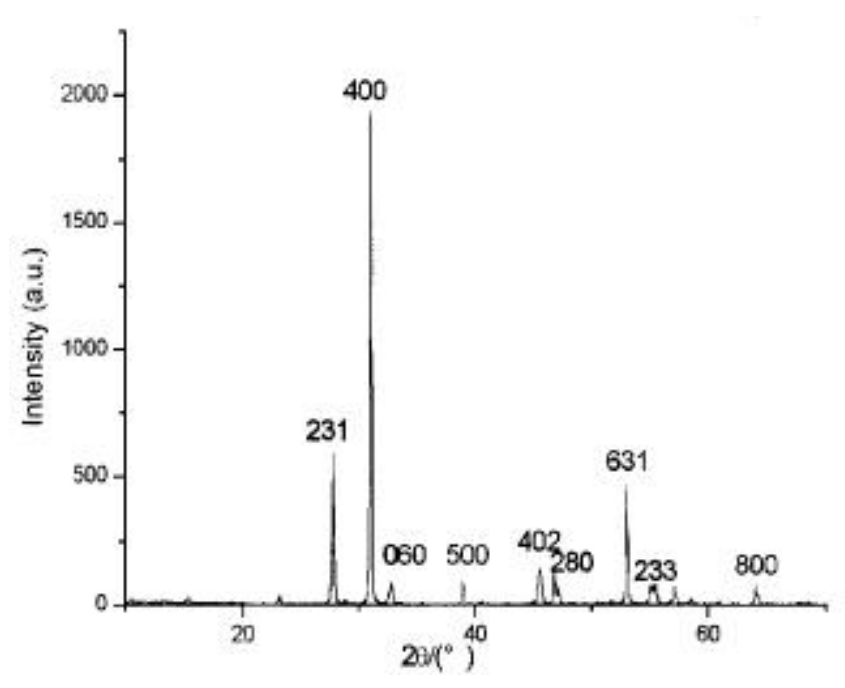

Figure 4. The XRD pattern of the as-grown crystal.

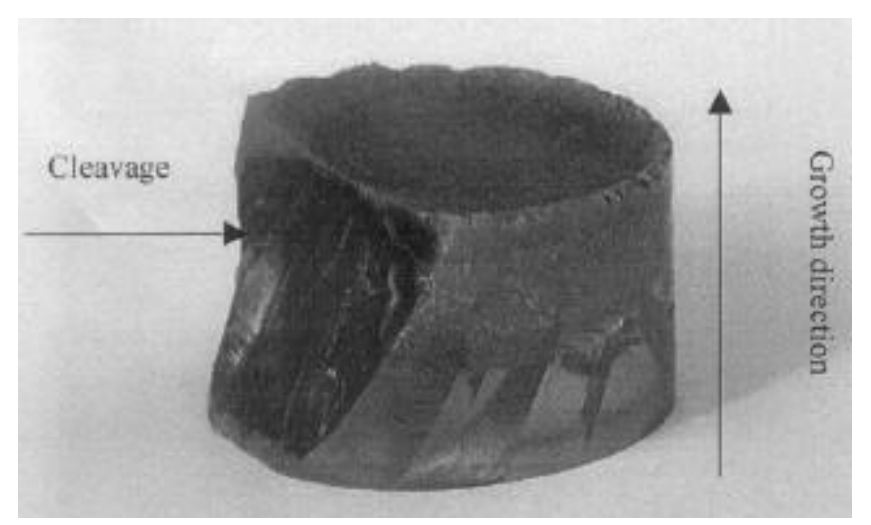

Figure 5. The cleavage in the top part of $\mathrm{Bi}_{2} \mathrm{TeO}_{5}$ crystal. 


\section{Conclusions}

$\mathrm{Bi}_{2} \mathrm{TeO}_{5}$ crystals were grown by the modified vertical Bridgman method from its stoichiometric melt. The melt was sealed in the limited space of the Pt crucible and the evaporation of $\mathrm{TeO}_{2}$ was controlled effectively. Small temperature gradient and in situ annealing process were employed during crystal growth and the occurrence of cracking was reduced considerably. Transparent and crack-free $\mathrm{Bi}_{2} \mathrm{TeO}_{5}$ crystal up to $25 \mathrm{~mm}$ in diameter and $40 \mathrm{~mm}$ in length had been grown successfully.

\section{References}

Berger G, Denz C, Foldvari I and Peter A 2003 J. Opt. A: Pure Appl. Opt. $5 \mathrm{~S} 445$
Ding Jiaxuan, Wu Anhua and Xu Jiayue 2004 Bull. Mater. Sci. 27333

Foldvari I, Peter A, Voszka R and Kappers L A 1990 J. Cryst. Growth 10075

Foldvari I, Liu H, Powell R C and Peter A 1992 J. Appl. Phys. 715465

Foldvari I, Peter A, Szakacs O and Munoz F A 1999 J. Crystal Growth 198/199 482

Kumaragurubaran S, Krishnamurthy D, Subramanian C and Ramasamy P 2000 J. Crystal Growth 209855

Peter A, Szakacs O, Foldvari I, Bencs L A and Munoz F 1996 Mater. Res. Bull. 311067

Szaller Zs, Poppl L, Lovas Gy and Dodony I 1996 J. Solid State Chem. 121251

Wu Xianjun, Xu Jiayue, Xiao Jingzhong, Wu Anhua and Jin Wenqing 2004 J. Crystal Growth 263208 